\title{
Nasopharyngeal Cancer pT3 TNM Finding v6
}

National Cancer Institute

\section{Source}

National Cancer Institute. Nasopharyngeal Cancer pT3 TNM Finding v6. NCI Thesaurus. Code C64462.

Nasopharyngeal cancer with tumor involving bony structures and/or paranasal sinuses.

(from AJCC 6th Ed.) 